\title{
Review of Decentralization in the Health Management in Shiraz University of Medical Sciences
}

\author{
*Mohsen Jajarmizadeh \\ Assistant Professor, Department of Management, Payame Noor University, I.R.Iran \\ Email:m.jajarmizadeh@yahoo.com
}

\section{Farzaneh Mohammadi}

Master of Public Management, Department of Management, Payame Noor University, I.R.Iran

\section{Doi:10.5901/mjss.2016.v7n5s1p125}

\begin{abstract}
In this study, researchers examined the organizational factors influencing the decision-making system is Shiraz University of Medical Sciences. The study sample consisted of 500 managers of which 230 of them were selected by simple random sampling. This study in term of aim is applied and in term of method correlation is researcher has used a questionnaire to collect information. To analyze the data descriptive statistics (mean, frequency and standard deviation) and inferential statistical methods (regression, analysis of variance and independent $t$-test) were used. The results showed the acceptance of the main hypothesis of this study that there is a significant relationship between organizational factors influencing the decision making (management style, features of delegation and location of the organization) and decentralization in health management. In determining the components of effective decentralization also using stepwise regression from the first to the ninth stage, manager tolerance of ambiguity, mental ability, interest in the job and the importance of keeping it lower tolerance of ambiguity, positive perception and attitude of the manager to a subordinate, the type of tasks, size, clarity of policies and programs and align individual and organizational goals has showed largest share in better decentralization in health management. It also features with the most influential dimensions delegates and location of organization was diagnosed.
\end{abstract}

Keywords: decentralization, health management, decentralization, delegation of authority.

\section{Introduction}

Iran Health system with rapidly social, economic and technical changing, faced with many challenges and issues related to equity, quality, relevance and effectiveness of risk. In this regard, centralization is a major cause of inefficiency in the past decades as a world-wide, especially in developing countries is used.As the institutions have developed, models of decentralization has been introduced and tested and patterns have lasting effects and the evolutionary process has been costly. Casual and experiences over the years based on the personal judgment provided the first approximate responses and in recent decades in Western countries has begun systematic assessment of these replies (Noravesh, 1998). In terms of political and administrative knowledge used centralization and decentralization term in the current time in a state of ambiguity in many cases and the roots of this ambiguity is in the social and political ideologies of the society. The point that should be noted is that decentralization is not manifested in practice as absolute but relative is imagined with varying degrees of concentration.

\section{Statement of Problems}

In an organization where decisions are taken? At the top of the organizational hierarchy or down by senior management by people who decide to be closer to what is on it? Concentration mainly refers to the levels of the hierarchy can be an authority to take decisions. Organizations concentration on senior managers and those who are at the top of organizations are making the right decision.In decentralized organizations the decisions taken at lower levels (Daft, 2010: 187).

The concepts in political science and administrative centralization and decentralization in a variety of important and complex is used. The roots of this ambiguity in the political and social views and opinions of the community,so that in any kind of political and social system rather than the extremes of centralization of power and decision-making is 
seen.Centralization and decentralization in any form and shape is an expression of power in decision-making.The point that should be noted is that the concept of centralization and decentralization in practice and the emergence of expression is not absolute, but imagine it is something relative with varying degrees of concentration (Mir Hosseini, 2006: 26).

According to Mintzberg, the centralization and decentralization in the organization depends on its organizational structure and mechanism of coordination. Centralization and decentralization because of different definitions and changes so much is one of the dimensions of the opaque and complex structure. (Robbins, 2008: 96). Assignment will be provided to stimulate or motivate employees. Research results show that people feel they should be effective and should be given that the results or performance is achieved. If you increase the power of employees and members of the organization they will more motivated to get things done, because they want to increase their effectiveness and has always sought to use their initiative and creativity to do. Most people feel or wish to join organizations that do good work. Transfer phenomenon, will enable them meet demands and wishes of action. Demonstrate skill mastery, competence is one of the rewards which will be placed in this way (Daft, 2010: 476). The purpose of the delegate or delegation of authority to the staff is that four factors have placed these people, so they can do a better job or task. They are: information, knowledge, power, and rewards (Daft, 2010: 477). Health system in an environment with rapidly changing social, economic and technical acts leads to many challenges and stresses that, in response to the problems and challenges arising from the need for equity, quality, relevance and effectiveness of reforms with the basic features, targeted and sustainable health care system is essential.One of the reasons for failure and lack of efficacy in the treatment and production and finance functions, centralization is severe involvement.

Decentralization as a process to promote good health system and an integral part of broader reforms improve equity, efficiency,quality and economic feasibility is known around the world, especially in Latin America, Asia, Europe and Africa, forty years ago is ongoing.Despite several laws enacted in the past decade, little action has been taken in this regard in Iran and Iranian health systems as one of the most complex health systems in the world over the past decade than the strategy of primary health care that reformed is seen (Jabari, Tabibi, Delgoshaei, Mahmoudi, Bkhshian2007: 33). But the context of this work in recent years with the Council approved the program of reform and development, different policies to privatization and divestiture of some units and the service and support to non-governmental sector have been taken. Since the approaches taken in different countries is not always successful and health system reform cannot be a global or even regional units followed the formula and the design and implementation of appropriate models of decentralization, the reform process has been effective and can use the health care system will not need foreign experts and the research was designed and done.

\section{Importance of Research}

Here it seems if we find we have an overview of the health system in the last two decades this system goals such as increasing access to services, increased longevity, life expectancy, lower infant mortality and birth rate control some success has been remarkable.On the other hand, like many developing countries the following problems: inefficiency of service, quality declined, different access to health care, spending by households and so on. This has led stakeholders including the public health system, service providers, insurance companies and policy-makers have expressed their dissatisfaction with the government is trying various strategies to solve the problem they meet.One of these solutions is outsourcing the services and allowances to invest in the institutions they previously ran the government.In the past two decades in the health sector plans have been implemented in this regard that can refer to the self-hospitals.In the third five-year plan in Article 192 clearly states the decentralization in the health sector.It stressed the development of health centers in areas where there is no possibility of investing in private and cooperative sectors can be done by the government.Also, the Ministry of Health and Medical Education were allowed to purchase services from its employees in accordance with the definition of approved tariffs (rather than the individual work day) of the non-governmental sector to act.

It is listed in the Regulations on the development of rural and urban health centers, except where the cooperative sector, private and charitable diagnosed with Ministry of Health, treatment and medical training, except in cities where there are no bids, will be carried out by the government. The regulations on the transfer of health units included the Ministry of Health and Medical Education through the management transfer (no transfer of ownership of capital) and other methods can be rented units run health and education completely or part of it or some legal services to individuals or concede. As stipulated in article 7 of the bylaws of the Ministry of Health and Medical Education through the transfer of ownership of an asset can transfer or hire the hospitals, pharmacies and labs, etc. are subject to this law to the entities and non-governmental organizations (cooperatives, private and charitable). Decentralization and organizational 
characteristics, in which a significant amount will be transferred to the lower levels decentralization to centralization, when the amount is transferred to the lower levels of the organization, decentralization has been more rapid decision making and implementation of decisions are possible with special conditions. When only a limited amount of delegate is available, the concentration is characterized by uniformity of policies and guidelines and close control.Decentralized factors in an organization, the decentralization of the organization's managers need to apply to the particular situation.Specific questions to determine the degree of decentralization for each situation are:

What is the current size of the organization? The larger the organization, the more likely it is that decentralization is useful. Whatever the size of a larger organization, the managers must take responsibility for more and different tasks. Transfer of authority is the effective tool to help managers in order to tolerance work load has increased. What places are the customers? As a general rule, the customer physically apart, the decentralization is larger, efficient and effective. Decentralized location, close to customers and provides management resources and cause rapid customer service. Typically, decentralization may be the potential confusion caused by a variety of sources to create a separate organization to minimum and appropriate decisions taken in connection with the production process. Where are the suppliers of the required goods of organization? The raw materials from which the products are produced, is considered another important factor. Once lost, and perhaps even the cost of sea transport of raw materials from far distances, from the supplier to the factory, which leads to the decentralization of support functions.

Do you need quick decisions to be taken in the organization? If the organization is required to make quick decisions, decentralization may be necessary.Decentralization avoids of waste procedures, and to subordinate to the authority granted to him allowdeciding that you need. The transfer of power when is rational someone received the power potentially capable of decision-making, and if he is lacking this ability, quick decision making has not the benefit for the organization. Is Creativity good for the organization? If desired, creativity, degree of decentralization may seem logical.Decentralization to someone has been granted the freedom to find better way to conduct business.

\section{Theoretical Research}

\subsection{Centralization and decentralization in management}

The concentration is levels of the hierarchy of powers that is to-be take decisions. In centralized organizations, senior managers and those who are at the head of the organization have the right to decide.In decentralized organizations the decisions taken at lower levels.

Decentralization is one of the unsolved mysteries in the organization, and in the organization observe bureaucracy, hundred percent, all decisions are taken by the top management of the organization.And $\mathrm{He}$ is in full control of the organization.But the larger the organization and increasing the number of employees, entities and bodies, not all decisions can be referred to the supreme authority of the organization, or the amount of deciding reach to the extent that a senior official could not tolerate it. The results of the research that has been done on large organizations show that more decentralization phenomenon observed in large organizations (Daft, 2010: 187).

Decentralization is usually interpreted two types: (1) distribution option 2 - geographical distribution, the latter interpretation is incorrect because only the decentralization of authority to lower levels of the organization. Because of the mistakes that have geographically dispersed organizations that often lack concentration but the units and departments alone is not evidence of decentralization. Decentralization is organizational feature in which a significant amount will be transferred to the lower levels.Decentralization to centralization - when the amount is transferred to the lower levels of the organization, decentralization has been more rapid decision making and implementation of decisions are possible with special conditions.When only a limited amount of delegate is available, the results are characterized by uniformity of policies and training and close control (Allagheband, 2005: 100).Decentralization refers to the transfer or assignment of power or decision-making authority planning or management of the central government or its affiliated organizations, field dressing, subordinate units of government, semi-autonomous public companies, local authorities or NGOs.(ShabrChyma and Randyly, 1994: 15) when the power is vested in the distribution or Decentralization occurred (Monavvarian, 1999: 6).

RahmanSeresht (1993), first to understand the concept of "centralization" and "decentralization" has identified three common concepts of concentration and it is necessary to note that our purpose in this discussion is the third concept. These concepts include:

A) Regional concentration, regional concentration refers to accumulate the kind of activities, services, goods or facilities in a particular geographic area.

So the Tehran and Suburbs Bus Company, which offers services only within the Tehran and Suburbs, an example to concentration on a type of activity in a particular area is a gathering of health and medical facilities 
in Tehran can be cited as an example of the area concentration.

B) organizational or unit concentration: If only one of the units of an organization a country with one of the organizations responsible for the officer to do a specific task or mission is not authorized to perform the task or mission, even departments or units make or if you have several departments or units, only two of them for permission to use one of its own duty, there is concentration on a specific task or mission or organizational unit. Thus, for example, meat distribution south of the country, because services and goods from the center of Kerman province are out of ranges but do not count toward Kerman regional concentration and is an organizational concentration. If the Ministry of Education is only one of its units responsible for the implementation of all matters pertaining to the deployment of teachers to the schools its subsidiaries abroad, has created a kind of concentration. Only one of its subordinate units as well as the organization in charge of repairing all of typewriters or follow the old Binding library of its units is to create a single concentration.

C) Decision-making: authority or power that high authorities of an organization have to most important decides defined as concentration. It is obvious that low-ranking officials to participate in major decisions, decreased concentration synonymous. Thus, if the low-ranking officials of an organization do not have any authority to make important organizational decisions their highly centralized organization will be considered when these authorities, to make some important decisions to be made, the concentration will be reduced. It is obvious that low-ranking officials to participate in major decisions decreased synonymous concentration.

Kroizer (1966) findings are entirely separate receipts. He felt like a bureaucratic decision-making power is concentrated in the central office of the director and it seems that the rules they have created jobs and has the same focus and direct supervision of all proportion as labor standards to replace this supervision of the non-focused.He decides that its employees share their wealth of evidence showseffort made towards democracy has led to more focus (Fiedler, 1966; Proshansky and Sidnbrg, 1966).

\subsection{Centralization and decentralization in the world:}

As a long time business cannot be fully centralized or non-centralized control through a relationship in the world to operate effectively.As America suggests classical management principles there should be a balance between centralization and decentralization.According to studies done on how multinational companies to successfully implement global strategies, subsidiary of Affiliated Managers announced that effective implementation requires a balanced relationship and the balance in the decision-making process applied to the world as a tool to balance control relationship between centralization and decentralization (Radrigz, 2000: 428).

Centralization and decentralization are affected by a combination of factors, the most important of these factors include educational theory, environmental conditions, priorities ofsenior management, and the focus of education ultimately leads to the loss of local control (Robert, 1981:1).

In what circumstances is permissible centralization?

1. The Director shall have strong information systems at macro-level.

2. The manager must have a control system.

3. The Director must be a mature work and expertise in their work.

4. Variety of jobs impact on decentralization (Alice, 1991: 57).

\section{Theoretical Framework}

Clear theoretical framework for the study is a detailed description of the scientific research on the subject of research and defines the basic concepts of research and dependencies between them and drawing on the conceptual framework of the theory beginning question will be addressed (Keiwi and Kapnhvd, 2006: 100). A series of studies to determine the degree of centralization or decentralization literature show this requires a close relationship with the status and structure of the organization and related factors affecting the structure, and on the other issues that affect the behavior and skills of managers (as are delegated authority) Minister (for those delegated authority) is (Desler, 1993:153). In other words, the theory of a serious share of the relevant factors in determining the degree of focus within the organizationand on the other hand a serious role in managing behavioral theories cannot be ignored so, according to both the above-mentioned theories friend can be achieved comprehensive research on the subject. First, we examine the management style and its influencing factors based on behavioral theory of our study. Management style interpreted in a certain way to make you understand performance (Rezaeian, 1993: 158).

In this case, four factors can be considered that effect on leadership style. 
1) Manager's value system, which includes answers to questions such as the administrator how much really think that his subordinates in decision making can be effective.

2) Trust in subordinates that the degree of control or freedom given depends by managers to employees if the director believes to subordinates based on the $x$ assumption that humans are basically considered lazy and unreliable and irresponsible assumptions and or vice versa based on theoretical y assumptions are known creative and responsible.

3) Manager's interest depends what are the managers feel more comfortable.Some managers have the authority (centralized control) feel that on the contrary, others are comfortable in collaborative situations.

4) A sense of security in an uncertain positions also binding up on the manager's willingness to give up control on the decision to other people in an insecure environment for any amount that is less tolerance of ambiguity, he tends to focus on decision-making. The practical realization of a particular management style and characteristics depends on the expectations of employers and managers to delegate authority for them. Hersey Blanchard several factors for this purpose are the count and the expression that his subordinate's administrator can grant more freedom in terms of basic conditions.

If subordinatesneed to relatively highautonomy

If the subordinates have a readiness to accept responsibility for decisions

If you are interested and feel it is important

If you understand the goals of the organization to be coordinated with them

If you have the knowledge and experience necessary to deal with the problem

If you expect to participate indecision-making and in this case they are trained

But as mentioned factors concerning behavioral view to management determines the concentration or decentralization decision-making.But other factors are involved, based on structural approaches that are main indicators first with degree of complexity of the organization second, the degree of recognition of the organization, third, centralization or decentralization factors directly linked. Explaining complexity of organization horizontal separation indicators and division of tasks should be considered carefully.The parameters of vertical separation and recognition of hierarchies and measures of spatial separation and their organization geographical distribution is accurate (Kabiri, 1992: 176-178).

Experts believe that adaptation to dynamic and complex environments on the other hand and creative professionals on the one hand and lead to trend toward decentralization and flexible and organic structure (Seyed Javadein, 2007: 392). According to the theory Mintzberg (1992), concentration or decentralization in five of the structure and model of car, professional, part, including the complexity and dynamics of simple and organizational internal factors at the level delegates. Delegate are those characteristics and working relations in the field of middle managers and operational features in recent delegate and labor relations managers and excellent professional relationship and support staff with lower levels are considered.

\section{Analytical Framework}

According to the theoretical framework of the a forementioned factors affecting the level of centralization and decentralization at three dimensions of environmental factors, factors related tomanagementstyle andfactors related to the characteristics of those categories which are delegated ,Jajarmizadeh(1995), these three components in the conceptual model of centralization and decentralization has designed.

This model is also taken from the above-mentioned research is presented in the figure below.

Figure 1 analytical framework: factors affecting thedecision-making system 


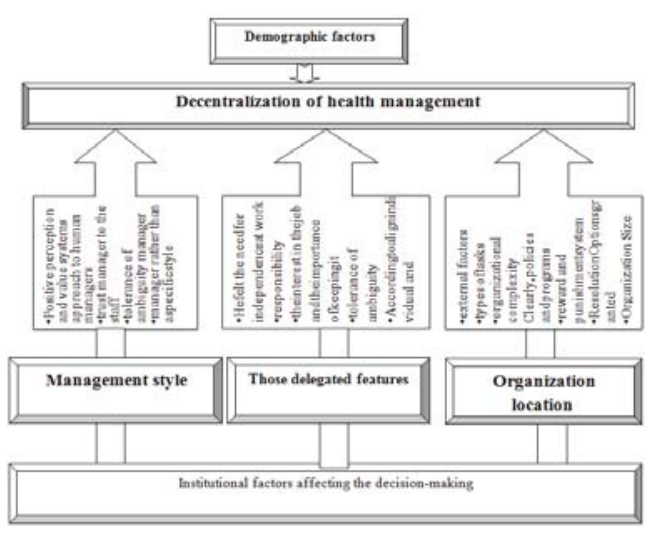

Figure 1- Conceptual Framework

\section{Research Methodology}

This research has practical purpose because its emphasis on the application of its results in solving specific problems of society and in theory it does not exist.Based on a description of the correlation in this study, because we want consider the relations between one or more factors to consider with one or more other factors. Methods in this study descriptive correlational survey because the relationship between organizational factors influencing the decision-making and decentralization of health management will be discussed in this context, information is collected through a survey.

\section{The Population, Sampling Method and Scope of Time and Place}

The population of the research consisted of staff of Shiraz University of Medical Sciences and subordinate units to 500 people. The study was conducted at the management level. The random sampling method was used for sampling. And to select a sample size between individuals the general formula Cochran where possible relationship and no relationship is considered 0.5 , which is used a sample size of 230 is obtained. Place was the general framework of Shiraz University of Medical Sciences and is affiliated units and the research observer delegation and the quality of the centralized and decentralized decision-making at the University and affiliated units. The time frame of this study was general and administrative structure of Shiraz University of Medical Sciences and it's a subsidiary in 2014. Mainly focusing on the current state of decision-making, understanding the patterns of centralized and decentralized authority will currently.

In this research study is to evaluate the assumptions and parameters relating to these assumptions, direct interviews with staff, library studies, online surveys and questionnaires produced by Jajarmizadeh (1995) were used which consists of two parts. The first part of question demographic and the second part of institutional factors that affect the decision-making and decentralization of the system using a Likert scale is measured.

\section{Findings}

- There is a significant relationship between organizational factors affecting the decision-making and decentralization in the management of health.

Table 1. Significant regression organizational factors influencing the decision-making and decentralization of management

\begin{tabular}{|c|c|c|c|c|c|}
\hline Model & \multicolumn{2}{|c|}{ Non Standardized } & Standardized & $\mathrm{t}$ & Significant level \\
\hline \hline & B & Standard error & Beta & & \\
\hline Width of origin & 0.731 & 0.813 & & 0.898 & 0.37 \\
Organizational factors & 0.073 & 0.005 & 0.665 & 13.435 & 0.000 \\
\hline
\end{tabular}


According to the Tables 1 the statistic (13.435) in the alpha 0.05out of the acceptance of null hypothesis, the hypothesis according to there is a significant relationship between organizational factors influencing the decision-making and decentralization in the management of health will be accepted.

- There is a significant relationship between the management style and decentralization in the management of health.

Table 2. Significant regression management style and decentralization on health management

\begin{tabular}{|c|c|c|c|c||c|}
\hline \multirow{2}{*}{ Model } & \multicolumn{2}{|c|}{ Non Standardized } & Standardized & \multirow{2}{*}{$\mathrm{t}$} & \multirow{2}{*}{ Significant level } \\
\cline { 2 - 4 } & $\mathrm{B}$ & Standard error & Beta & & \\
\hline Width of origin & 6.473 & 0.685 & & 9.445 & 0.000 \\
Management style & 0.122 & 0.016 & 0.448 & 7.557 & 0.000 \\
\hline
\end{tabular}

According to Table 2 the statistic (7.557) in the alpha 0.05out of the acceptance of null hypothesis, the hypothesis according to there is a significant relationship between management style and decentralization in the management of health will be accepted.

- There is a significant relationship between positive perception and manager's attitude value system to human and decentralization in the management of health.

Table 3. Regression significant positive perceptions and manager's attitude value system to human

\begin{tabular}{|c|c|c|c|c|c|}
\hline \multirow{2}{*}{ Model } & \multicolumn{2}{|c|}{ Non Standardized } & Standardized & \multirow{2}{*}{$\mathrm{t}$} & \multirow{2}{*}{ Significant level } \\
\cline { 2 - 4 } & $\mathrm{B}$ & Standard error & Beta & & \\
\hline \hline Width of origin & 7.852 & 0.645 & & 12.011 & 0.000 \\
Positiveperceptions & 0.202 & 0.035 & 0.357 & 5.778 & 0.000 \\
\hline
\end{tabular}

According to Tables 3 the statistic (5.778) in the alpha 0.05out of the acceptance of null hypothesis, the hypothesis according to there is a significant relationship between positive perception and manager's attitude value system to human and decentralize in the management ofhealth will be accepted.

- There is a significant relationship between the trust managers to employee with decentralization in the management of health.

Table 4. Significant regression manager's trust to the staff

\begin{tabular}{|c|c|c|c|c|c|}
\hline \multirow{2}{*}{ Model } & \multicolumn{2}{|c|}{ Non Standardized } & Standardized & \multirow{2}{*}{$\mathrm{t}$} & \multirow{2}{*}{ Significant level } \\
\cline { 2 - 4 } & $\mathrm{B}$ & Standard error & Beta & & \\
\hline \hline Width of origin & 7.169 & 0.66 & & 10.871 & 0.000 \\
Manager'strust & 0.383 & 0.056 & 0.41 & 6.79 & 0.000 \\
\hline
\end{tabular}

According to Tables 4 the statistic (6.790) in the alpha 0.05out of the acceptance of null hypothesis, the hypothesis according to there is a significant relationship between trust manager to employee with decentralize in the management will be accepted.

Also according to the table, standard value of the variable trust manager to employees as predictor variables and decentralization in the management of health as the criterion variable are 0.410 that this amount represents a direct correlation between the two variables.

- There is a significant relationship between characteristics of those delegated with decentralization in the management of health. 
Table 5. Significant regression features of those delegated

\begin{tabular}{|c|c|c|c|c|c|}
\hline \multirow{2}{*}{ Model } & \multicolumn{2}{|c|}{ Non Standardized } & Standardized & \multirow{2}{*}{$\mathrm{t}$} & \multirow{2}{*}{ Significant level } \\
\cline { 2 - 3 } & $\mathrm{B}$ & Standard error & Beta & & \\
\hline Width of origin & 1.161 & 0.718 & & 1.618 & 0.107 \\
Features of those delegated & 0.197 & 0.013 & 0.697 & 14.668 & 0.000 \\
\hline
\end{tabular}

According to Table 5, the statistic (14.668)in the alpha 0.05out of the acceptance of null hypothesis, the hypothesis according to there is a significant relationship between features of those delegated with decentralize in the management will be accepted.

Also according to the Table, standard value of the variable features of those delegated as predictor variables and decentralization of health management as the criterion variable are 0.697 that this amount represents a direct correlation between the two variables.

- There is a significant relationship between accountability and decentralization in the management of health.

Table 6. Regression significant responsibility for the decentralization of health management

\begin{tabular}{|c|c|c|c|c|c|}
\hline \multirow{2}{*}{ Model } & Non Standardized & Standardized & $\mathrm{t}$ & \multirow{2}{*}{ Significant level } & \multirow{2}{*}{ Model } \\
\cline { 2 - 5 } & Beta & $\mathrm{B}$ & Standard error & & \\
\hline Width of origin & & 7.187 & 0.609 & 11.803 & 0.000 \\
Accountability & 0.439 & 1.224 & 0.166 & 7.37 & 0.000 \\
\hline
\end{tabular}

According to Table 6, the statistic (7.370) in the alpha 0.05out of the acceptance of null hypothesis, the hypothesis according to there is a significant relationship between accountability and decentralization of management will be accepted.

- There is a significant relationship between the organization's situations with decentralization in the management of health.

Table 7. Regression significant position with organization's situations with decentralization in the management of health

\begin{tabular}{|c|c|c|c|c|c|}
\hline \multirow{2}{*}{ Model } & \multicolumn{2}{|c|}{ Non Standardized } & Standardized & \multirow{2}{*}{$\mathrm{t}$} & \multirow{2}{*}{ Significant level } \\
\cline { 2 - 4 } & $\mathrm{B}$ & Standard error & Beta & & \\
\hline \hline Width of origin & \multirow{2}{*}{1.1360 .193} & 0.902 & & 1.26 & 0.209 \\
Organization's situations & & 0.017 & 0.611 & 11.644 & 0.000 \\
\hline
\end{tabular}

According to Table 7, the statistic (11.644) in the alpha 0.05out of the acceptance of null hypothesis, the hypothesis according to there is a significant relationship between organization's situations and decentralization of management will be accepted.

- There is a significant relationship between external factors with decentralization in health management.

Table 8. Regression significant external factors with decentralization in health management

\begin{tabular}{|c|c|c|c|c|c|}
\hline \multirow{2}{*}{ Model } & \multicolumn{2}{|c|}{ Non Standardized } & Standardized & \multirow{2}{*}{$\mathrm{t}$} & \multirow{2}{*}{ Significant level } \\
\cline { 2 - 4 } & $\mathrm{B}$ & Standard error & Beta & & \\
\hline \hline Width of origin & 8.081 & 0.729 & 0.304 & 11.09 & 0.000 \\
Externalfactors & 0.558 & 0.116 & 4.818 & 0.000 \\
\hline
\end{tabular}

According to Table 8, the statistic (4.818) in the alpha 0.05out of the acceptance of null hypothesis, the hypothesis 
according to there is a significant relationship between external factors with decentralize in the management will be accepted.

- There is a significant relationship between the types of duties with decentralization in the management of health.

Table 9. Regression significant types of duties and decentralization in the management of health

\begin{tabular}{|c|c|c|c|c|c|}
\hline \multirow{2}{*}{ Model } & \multicolumn{2}{|c|}{ Non Standardized } & Standardized & \multirow{2}{*}{$\mathrm{t}$} & \multirow{2}{*}{ Significant level } \\
\cline { 2 - 4 } & $\mathrm{B}$ & Standard error & Beta & & \\
\hline \hline Width of origin & 8.195 & 0.729 & & 11.243 & 0.000 \\
Types ofduties & 0.539 & 0.116 & 0.295 & 4.654 & 0.000 \\
\hline
\end{tabular}

According to Table 9, the statistic (4.654) in the alpha 0.050ut of the acceptance of null hypothesis, the hypothesis according to there is a significant relationship between types of duties and decentralization of management will be accepted.

\section{Conclusion and Research Barriers and Suggestions}

The share of dimensions (management style, feature of those delegated and organization location) in decentralization and that is one of the aspects of the decentralization is more effective, it must be said that given the characteristics of respondents and the two-dimensional position that the organizational aspects influencing the decision was the largest in anticipation of decentralization in the management of their health.And in response to which one of the dimensions of decentralization is more effective, it must be said that given the characteristics of the respondents, according to health professionals have the greatest impact.

The study of share of high dimensions and components, as in previous discussions and noted research theoretical framework, positive perception and managers attitude to human value system, trust manager to employees, tolerance of ambiguity, director, manager rather than a specific style, felt the need for independence in work, responsibility, interest in the job and the importance of counting, tolerance of ambiguity subordinate, believed to align individual and corporate goals, management experience, intellectual ability, external factors, types of tasks, organizational complexity, clarity of policies and programs, reward and punishment system, clearly the powers granted and the size of the components of organizational factors influencing the decision were included in this study.To determine the contribution of each of these components of decentralization in the health management stepwise regression were used.And director, respectively, tolerance of ambiguity, mental ability, and interest in the job and the importance of keeping it lower tolerance of ambiguity, positive perception and attitude of the director of human value, type of work, size, and clarity of policies and programs and to align individual and corporate goals as the largest share in decentralization. Other organizational factors listed in the survey were excluded due to overlap.Decentralization is that each member can take the necessary decisions regarding the amount of duties and responsibilities.

Improving environmental conditions, organizational development, extensive knowledge of high-level managers with organizational problems and the appearance of the adequacy of management capabilities and lower levels are the main reasons for the trend toward organizational decentralization. Different organizations have different organizational structures with a variety of decentralization. And four concentrated source of decision-making and lower the degree of concentration in organizational decision making are: one, during the life of the organization, technology (production), environment, and decentralization is associated with a high level of complexity. The person controlling the decisionmaking process is used as a measure of concentration. Decentralized an immediate solution to solve administrative problems, political or economic is not a classic management principles as Americans show there should be a balance between centralization and decentralization have been raised that this will be achieved balance process. Decentralization requires that the authority delegated to those who give and those who take the concept of decentralization are well understood. To achieve equitable growth policies, decentralization and planning is essential.

This study, like other research and studies, faced with constraints that refer to some of them here:

1. Most participants believe that such research has little to do and these things were considered useless. The cooperation is very difficult.

2. Most of the subjects were acting in response to questions more conservative with their mediocrity check. 
3. The lack of cooperation and hard too and the staff of libraries and research centers, universities and agencies and do not allow the use of theses in the library and the following cases for decentralized health care system will be introduced in the functioning of the provision of services to the low-cost options for successful decentralization of other functions in our health:

1. The development of scientific and professional associations in the province

2. The transfer of development (human, equipment and physical space) University of Medical Sciences in the universities

3. The delegation of welfare and social groups such as drug addicts, the disabled, the elderly and children, or the municipalities to the Ministry of Welfare

4. The combination of public and private sector in the provision of services

5. The management style is based on decentralization

6. Strengthen the positive perception of their attitudes and value systems

7. Strengthening the trust manager to the staff

8. Enhance the tolerance of ambiguity health managers

\section{References}

Alice, I (1991). Here come the hibrids.computerword,29,57- hibrids.computerword,29,57-93

Allagheband, AS. (2005). General management. Tehran: Mental publication. (In Persian)

Bossert T, Beauvais J. (2001). Decentralization of health systems in Ghana, Zambia, Uganda \&Philippines. Health Policy \& Planning, 17(1), 14-31.

Crozer,M(1964). The bureaucratic phenomenon ,Chicago: university of Chicago press.

Daft, Richard L. (2002), Theory and Design Organization, Mohammad Ali Parsaian and Seyed Moammad Arabi Arabs Tehran, Cultural Research Bureau, second edition. (In Persian)

Desler, G. (1993). Fundamentals of Management, Davood Madani Tehran, advance (In Persian)

Fiedler, $f(1966)$. The contingency model :A theory of leadership effectiveness .new York: Rinehart and Winston

Hersey, c. Blanchard, K. (1992). Organizational Behavior Management (Third edition, G. Kabiri, Translator) Publications (SID) (1996). (In Persian)

Hersey, P. and Blanchard, K.(1988).practice Hullinc: organization behavior

Jabari Beirami, H, Tabibi, S.J, Delgoshaei, B, Mahmoudi M Bakhshian, F (2007). A Comparative Study of the mechanism of decentralization in the provision of health services in different countries and presenting a model for Iran.Journal - Health Management Research, Vol. 10 No. 37, 40-33. (In Persian)

Jajarmizadeh, M. (1995), to evaluate the centralized and decentralized decision-making structure and design of optimal University Jihad, MA, Tehran University, Tehran (In Persian)

Keiwi, r. Kapnhod, L. (2006) Methods in the Social Sciences (Am, Nick Gohar, Translator) Tehran: vitriol. (In Persian)

Mir Hosseini, M. (2001). Some theoretical concepts and practical solutions lack and authority. Galaxy, 69,26-29 (In Persian)

Monavvarian, AS. (1999). Designing the organizational structure. Tehran: Public Administration Training Centre. (In Persian)

Noravesh,A( 1998). Decentralization and management systems, knowledge management journal, 41, 40-72 (In Persian)

Radrygz, C. (2001). In International Management (printing, n. Zahedi,.Danaeefard, Translator). Tehran: Sffar- Ashraghi. (In Persian)

RahmanSeresht, h. (1993). Organizational centralization and decentralization. Tehran's Allameh Tabatabai University. (In Persian)

Rezaeian, AS. (2004). theories of organization and editing of books Humanities University. (In Persian)

Robbins, A. (2008). Theory of structure and organizational design (published twenty-third, M. Alvani,.Danaeefard, Translator). Tehran: Saffar-Ashraghi (1942) (In Persian)

Shabrchyma, c., and Randynly, d. (1994). Implementation of decentralization plan in Asia: local resources for rural development (as. Hakimi, c. Mir, -Q. Zokaei, Translator). Tehran: Research and Evaluation rural issues (1983). (In Persian) 